system destroys many of the disseminated cells. He maintains that there is always good reason for some form of systemic treatment even after the most apparently complete operation. His attitude to disseminated disease is aggressive even when it is far advanced. He holds that treatment should never be withheld and that the discomforts of chemotherapy are tolerated more readily than those of advancing cancer and the apathy of therapeutic inactivity.

He employs every available weapon often combining immunotherapy with chemotherapy and the two together with radiotherapy. His belief in immunotherapy would not be echoed everywhere. It is possibly because this book was first published in 1976 that his enthusiasm appears untempered by the experiences of the past five years.

The author's style is frankly egotistical and he has not been well served by his translator. The first person singular peppers every page. Few authorities are quoted by name without being described as 'my friend'. The text is liberally adorned with anecdotes of the author's therapeutic triumphs after others had given up hope. There is a sense of paranoia about some of the writing and members of the profession unwilling to accept his views are treated to powerful strictures.

In general it may be said that this book is not an objective review of the current position of cancer written for the laity, so much as an emotional plea for Dr Israel's personal approach to treatment.

SIR RONALD BODLEY SCOTT Sevenoaks, Kent

\section{Practical Guide for Medical Officers for Environmental Health}

by Andrew B Semple and J K Johnston. Nuffield Provincial Hospitals Trust 1980. 75 pp. £2.50.

In 1974 the Medical Officer of Health became extinct. Public health doctors working for the local authority came together with medical administrators working in the Hospital Boards, and with doctors working in central government departments, to form the new medical specialty of community medicine. From being one of the mainstreams of public health, environmental health became a backwater, as prominence was given to epidemiology and health service management. Many of us who act as medical officers of environmental health, the new title, feel that this movement went too far, and that insufficient attention was being paid to environmental health matters.

In the short term this was relatively unimportant, because those who became medical officers for environmental health had been medical officers of health for many years and they were therefore able to carry on the work and maintain the standards. However, their worry was very much for the future because it was evident that the trainees in community medicine, who were the community physicians of the future, were not being properly prepared for their environmental health responsibilities.

This book provides not only a very useful check-list for trainees but a reference book for the community physician who is appointed as a medical officer for environmental health. It covers his function as a 'proper officer', namely his duties with respect to outbreaks of food poisoning and infectious diseases. The second part covers the contribution which a medical adviser can make to the manner in which the local authority should handle atmospheric and other types of pollution, and finally it covers the miscellaneous functions a medical officer of environmental health has to fulfil.

It is in this last section that his ethical problems are found. There is little ethical difficulty in intervening in infectious disease outbreaks or in problems of environmental pollution, for there one is justified by the knowledge that the actions taken against any individual are designed to protect third parties from harm. However, the medical officer of environmental health may be faced with particularly difficult decisions in the miscellaneous functions which he has inherited from the past. For example, for the powers invested in the local authority by Section $\mathbf{4 7}$ of the National Assistance Act of 1948. These allow for the compulsory removal of people who are not mentally ill, but who are deemed to be in need of 'proper care and attention' for their own good. Because this type of removal can have an adverse effect on a person, it is obviously an extremely difficult decision to make for an individual's own good, because a doctor has to override a person's opinion although admitting that he is capable of making valid decisions. [See page $14 \%$ of this issue-Ed.]

Secondly, the medical officer of environmental health is responsib for giving advice on housing applica: tions, and has to compare the needs of hundreds, sometimes thousands of families on inadequate data. He may find himself in the position of being only able to take a certai number of cases to Housing Com mittees for approval, and havinf to decide among two or three families which is the most 'deserving? Finally, the medical officer of environmental health may have act as the adviser on occupationat health matters to the local authorit and again this often poses very difficult problems which are similar to the problems tackled by occupas tional health doctors in other field?

I hope that this book will become not only a textbook but a curriculum to prepare the trainee properly ifp his functions as a medical officer of environmental health. Oxfordshire Area Health Authori Oxfort

Whole Person Medicine: 穴里 International Symposium

Edited by David E Allen, Lewis Bird, Robert Herrmann. Inte: Varsity Press 1980. 26I pp. No pric\& The editors have brought togeth the papers read in February 1979 at a symposium held at the Ora Roberts University School of Medp̄ cine in Tulsa, Oklahoma. The speakers, all except me from US and all committed Christians, ranged from a Yale medical student to distinguished academics in philón sophy, psychiatry, physiology, sur gery, gynaecology and a Harvard professor of ethics.

The twelve papers attempt tol define 'holistic' care, set it in historical and biblical perspective look at the conflicts and ills in ou? society and particularly within the medical profession, and bravelio and humbly look at the observed failings of modern care patterns. The issues are important, basic and, is the opinion of the reviewer, ung
avoidable.

Herein lies a problem. The reviewer, like the authors, sees the problem and its solution as self evident, an urgent need to deparচ from specialised disease orientate $\$$ 